\title{
BREAST CANCER: IS OBESITY A RISK FACTOR?
}

\author{
Anjali Sethi' ${ }^{1}$ Deepak Sethi², Dinesh Kumar Barolia ${ }^{3}$
}

${ }^{1}$ Assistant Professor, Department of General Surgery, Ananta Institute of Medical Sciences and Research Center, Kaliwas, Nathdwara, Rajsamand, (Rajasthan), India.

${ }^{2}$ Consultant Surgeon and J. S, Department of Surgery, RNT Medical College, Udaipur (Rajasthan), India.

${ }^{3}$ Senior Resident, Department of Surgery, RNT Medical College, Udaipur (Rajasthan), India.

\section{ABSTRACT}

Most epidemiological studies established obesity as an important risk factor for breast cancer. It is one of the few risk factors that women can modify. Now-a-days breast cancer is considered to be a life-style disease. The relation of obesity to breast cancer is complex one. Obesity is found to be associated with increased risk of cancer in post-menopausal women, but relation is reverse in pre-menopausal women. In these patients, obesity increases risk due to enhanced oestrogenic activity in obese females. Apart from it, other factors like Insulin-like Growth Factor (IGF-1), Leptin has also been involved. Due to big breasts in obese females there is delay in seeking medical attention, delay in diagnosis, poor response to surgery, chemotherapy, radiotherapy and associated complication during treatment. We study the effect of obesity (Weight, BMI, WHR) as a risk factor in occurrence of breast cancer in local population of Southern part of Rajasthan in India. We found no significant association between obesity and increased risk of breast cancer in local population of this region where women are multiparous, physically active and usually do not use exogenous hormones.

\section{KEYWORDS}

Obesity, Breast Cancer, Risk Factor, Body Mass Index, Waist-to-Hip Ratio, Body Weight.

HOW TO CITE THIS ARTICLE: Anjali Sethi, Deepak Sethi, Dinesh Kumar Barolia. “Breast Cancer: Is Obesity A Risk Factor?” Journal of Evolution of Medical and Dental Sciences 2015; Vol. 4, Issue 96, November 30; Page: 16136-16140,

DOI: $10.14260 /$ jemds/2015/2365

\section{INTRODUCTION}

Breast cancer is a malignancy of breast that is common in women and rare in men. Because breast is a superficial organ, it can be easily accessed by both patients and doctors. As the incidence of breast cancer increases, significant advances have been made in development of early detection method, less radical primary therapy, use of radiation and chemotherapy which have saved significant number of lives.

The quality of life in India is improving with improvements of socio-economic status. As the life expectancy increases, the cancer burden to society also increases. Apart from curative modalities, we must also think about preventive policies as an essential step. Definitive etiology of breast cancer has eluded the researchers. Breast cancer is now considered as a lifestyle disease. Lots of factors such as nutrition, lifestyle, high fat intake, age of menarche, age of first pregnancy, being overweight, use of HRT, age of menopause have been incriminated.

Breast cancer is considered to be a consequence of affluence and being overweight. Excess of adipose tissue leads to increased circulating oestrogen.

\section{ABBREVIATIONS}

BMI- Body Mass Index.

WHR- Waist-to-Hip Ratio.

HRT- Hormone Replacement Therapy.

CL- Confidence Limit.

IGF- Insulin-like Growth Factor.

Kg- Kilogram.

Mt- Metre.

Financial or Other, Competing Interest: None.

Submission 10-11-2015, Peer Review 11-11-2015,

Acceptance 21-11-2015, Published 27-11-2015.

Corresponding Author:

Dr. Deepak Sethi,

303, Akshansh Apartment,

Keshav Nagar,

Udaipur-313001, Rajasthan, India.

E-mail: deepanjali.d1972@gmail.com

DOI:10.14260/jemds/2015/2365
Obesity may further add insult to injury because lipid is more prone to oxidative damage as compared to protein and carbohydrate. In present study, we planned to find out association between obesity and breast cancer in local population of Southern part of Rajasthan in India.

\section{INCIDENCE}

Breast cancer is a global disease. Incidence of breast cancer is continuously rising in last few decades. It accounts for $33 \%$ of all female cancer and is responsible for $20 \%$ cancer related death in women. It also shows a widespread geographical distribution. There is many fold variation in incidence and mortality among different countries. In UK incidence was $74.4 / 1,00,000$ in 2003, where as in South Korea it was 2.6/1,00,000 (Cancer Statistics 2003). In USA 2,11,300 new cases were diagnosed in 2003 with mortality of 39,800 , which were raised to $2,32,000$ new cases with mortality of 44,000 in 2012.

In India it has now become the first most common cancer in women population, way ahead of cervical cancer. It accounted for $25.9 \%$ of all female cancer in 2008; figure was raised to $27 \%$ in 2012 . In India $1,15,000$ new cases were diagnosed in 2008 with a mortality of 5,300 , which raises to $1,45,000$ new cases and mortality of 70,000 in 2012.(1) For the year 2015, there would be an estimated 1,55,000 new cases of female breast cancer and about 76,000 women in India are expected to die due to disease.(2)

\section{METHODS AND MATERIAL}

In present study, we studied 50 clinico-pathologically diagnosed patients of breast cancer. Diagnosis was based on detailed history, clinical examination, diagnostic modalities like mammography, USG and confirmed by FNAC and Tru-Cut Biopsy. Obesity was measured by body weight (Kg), Body Mass Index (BMI-Weight/Height. ${ }^{2} \mathrm{Kg} / \mathrm{mt}^{2}{ }^{2}$ ) and Waist-to-Hip Ratio (WHR-Waist circumference-to-hip circumference ratio WC/HC). Waist circumference was measured just above the level of lateral iliac crest below lowest rib, and hip circumference under inferior rim of pubic symphysis in midline. 


\section{OBSERVATIONS AND DISCUSSION}

Among 50 patients who were included in our study, $48 \%$ were pre-menopausal and $52 \%$ were post-menopausal Distribution was almost similar in control group where 46\% were pre-menopausal and $54 \%$ were post-menopausal (Table 1). Mean age of breast cancer patients in our study was 48.32 years, which was similar in control group with 49.96 years (Table 2). Patient who were presented in stage I and II were considered as early stage and those in stage III and IV were considered as advanced stage.

In our study, $44 \%$ patients were in early stage and $56 \%$ in advance stage (Table 3). Mean weight in pre-menopausal patient was $48.50 \mathrm{Kg}$. (Control-49.87Kg.), while in postmenopausal patient mean weight was $55.88 \mathrm{Kg}$. (Control$59.37 \mathrm{Kg}$.) (Table 4, 5). In pre-menopausal women we found that women who weighed less than $50 \mathrm{Kg}$., $75 \%$ of them had advanced disease; while in post-menopausal women who weighed less than $50 \mathrm{Kg}$., only $45 \%$ were presented in advanced stage. A significant difference is seen between weight of pre- and post-menopausal patients $(\mathrm{P}<0.05,95 \%$ Confidence Limit), but no difference was found in both groups with their respective controls.

Mean height in pre-menopausal patients was $154.13 \mathrm{~cm}$ (Control $154 \mathrm{~cm}$ ). In post-menopausal patients, mean height was $150.50 \mathrm{~cm}$ (Control $152.15 \mathrm{~cm}$ ). We did not find any significant relation between height and breast cancer risk in both groups of patients $(\mathrm{P}<0.0595 \% \mathrm{CL})$ (Table 6, 7). Altered height may be an indicator of childhood energy intake.(3) It was shown that height is rather consistently related to breast cancer risk.

It has been hypothesized that height reflects mammary gland mass, which could be related to cancer risk.(4) It was proposed that genetic factors, diet and physical activity may affect hormone that interfere epiphysial closure during puberty.(5) Stoll has suggested that better nutrition accelerate growth hormone, which in turn increases level of IGF-1. IGF-1 and sex steroids result in mutagenic effect on developing mammary tissue in adolescence and concomitant increased risk of epithelial atypia and carcinogenesis.(6) Height might influence breast cancer risk through its positive association with follicular phase plasmaoestradiol.(7)

While the above studies suggest a positive association between height and breast cancer risk, our findings are similar to Sonnenscheirn.,(8) Franceschis.,(9) Zhangy.,(10) London SJ.,(11) who proposed that there is no association of height with breast cancer in both pre- and post-menopausal women when compared to their respective controls. Obesity is defined as too much body fat. It can be measured by various means. Most recent studies considered BMI as a better measure of obesity. It is measured by calculating the patient's weight (Kg.) divided by Height. ${ }^{2}\left(\mathrm{mt}^{2}{ }^{2}\right)=\mathrm{Kg} / \mathrm{mt}^{2}$ People who have BMI 18.5-24.9 considered as normal, 2529.9 as overweight and $>30$ as obese.

$\begin{array}{ll}\text { BMI Body } & \text { Weight Status } \\ 18.5-24.9 & \text { Normal } \\ 25.0-29.9 & \text { Overweight } \\ >30 & \text { Obese }\end{array}$

Central obesity is defined as WHR equal to or greater than 0.95 in men and 0.80 in women. In present series, the mean WHR in pre-menopausal patient is 0.81 (Control-0.84) and post-menopausal patient is 0.82 (Control 0.83) (Table 8, 9). In our study, we did not find any significant relation between WHR and breast cancer risk in both groups $(\mathrm{P}>0.05$, 95\%CL). Various studies support our finding in this aspect.(12,13,14,15) Schapira and Folson AR found a strong association between WHR and breast cancer risk.(16,17) It was proposed that upper body fat accumulation leads to increased triglycerides, which in turn lead to reduced Sex Hormone Binding Globulin (SHBG) and increased circulating oestradiol. Excess circulating androgen appear to be related to increased upper body fat distribution.(12) (Table 8, 9).

An association between breast cancer and obesity has been recognized for last 40 years. The exact mechanism for this increased risk is not fully understood. It is lifetime exposure to oestrogen that is important in initiation and progression of breast cancer lesion. Oestrogen and progesterone affect the rate of cell division proliferation. Proliferating cells are more susceptible to genetic errors during DNA replication leads to malignant transformation.(18)

In post-menopausal women, main source of oestrogen is conversion of androgen precursor androstendione in peripheral adipocytes to oestrogen; so the greater the amount of adipose tissue the greater the rate of conversion and the greater the exposure of breast cells to oestrogen. Premenopausal women who are obese have frequent anovulatory cycles that reduce their exposure to oestrogen.(19)

Obesity is associated with early age of menarche, late age of menopause and infertility, which maximize the number of ovulatory cycles. This increases lifetime exposure of mammary epithelium to oestrogen, which in turn increases breast cancer risk.(20)

Obesity is also associated with insulin resistance and leads to a state of hyper-insulinaemia. Insulin can stimulate mammary epithelium via IGF-1, which has a synergistic effect with oestrogen in promoting mammary carcinogenesis. Breast cancer cell lines have been found to secrete at least five distinct insulin like growth factors binding protein (IGFBP).(21) Apart from these factors, Leptin is also supposed to have a major role in obesity mediated carcinogenesis.

Leptin is multifactor neuro-endocrine hormone, a product of gene (ob). It was found that leptin levels remain significantly higher in obese women. It causes the stimulation of normal and tumor cells, migration, invasion and enhancement of angiogenesis; suggesting that this hormone can promote aggressive breast cancer phenotype which is oestrogen dependent.(22)

Obesity not only supposed to be involved in causation of breast cancer, but also affect its diagnosis and prognosis. Obese women are more likely to have big breasts and breast lump may be less obvious, which would lead to delay in seeking medical attention. It also seems to be associated with early axillary metastasis and more rapid growth of metastasis. Obese women had 1.53 times higher risk of lymph node metastasis compared to slim women.(23)

Axillary surgery is more difficult and challenging and associated with increased risk of axillary drainage and lymphedema.(24) Large breasts are associated with technical difficulty in providing adequate dose of radiotherapy and related complication.(25) When chemotherapy is given to these patients with standard schedule, they may be underdosed.(26) Most epidemiological studies indicate that obese women are at increased risk of post-menopausal breast cancer. $(27,28,29,30,31)$ Various case control and prospective cohort studies found an inverse relationship between BMI and breast cancer among pre-menopausal women.

BMI has a significant and inverse relationship (Relative Risk $=0.834$ ) in pre-menopausal women.(32) Yehard studied the risk of premenopausal breast cancer was 0.68 in women with BMI>30. In our study, we found mean BMI in premenopausal patient was 20.45 (Control-21.01). In premenopausal patients with $\mathrm{BMI}<20,83.3 \%$ patients presented themselves in advanced stage. In post-menopausal women, mean BMI was 25.16 (Control-25.83).

In post-menopausal women with $\mathrm{BMI}<20,60 \%$ present themselves in advanced stage. We did not find any significant relation between BMI and risk of breast cancer in both preand post-menopausal women when compared to their 
respective controls ( $\mathrm{P}>0.0595 \% \mathrm{CL}$ ). We found that $56 \%$ of patients were presented in advanced stage, out of which $53 \%$ of patients had $\mathrm{BMI}<20$. (Table 10,11)

Decreased BMI in patient who present in advanced stage can be explained on the basis of cancer cachexia. The aetiology of cachexia in most cancer is not known. No single unifying explanation can account for tissue wasting seen in cancer patient, rather several factors acting simultaneous or sequentially to varying degree produce common end result in cancer cachexia.

\section{SUMMARY}

Conclusively looking to obesity and cancer, there are various epidemiological studies examining body size and breast cancer, most frequently using BMI to evaluate the impact of obesity on cancer patient. Incidence of obesity and physical inactivity are increasing rapidly throughout the developed world. Substantial evidence currently indicates a link between obesity and increased risk of various cancers; eg. Breast, endometrial, colon, kidney, oesophagus.

There are also suggestions that risk is reduced among individual who are physically active. Cancer is a degenerative disease and therefore it increases with increasing lifespan. Patients of breast Cancer in Southern part of Rajasthan in India seems to defy this hypothesis with difference in mean age. It clearly alludes that obesity is not directly related to disease in this region. In the population we found that women have late menarche, early menopause, early age of first child fed their baby for longer period, usually do not use exogenous hormone.

They are usually lean and thin and involved in strenuous physical activity. All these factors put them in low risk group; and obesity was not found to be a risk factor for breast cancer. But still incidence is continuously rising in rural population in India. There may be certain other factors, which may play a role in breast carcinogenesis. We are still away to look for the factors for breast carcinogenesis in our local community.

\section{BIBLIOGRAPHY}

1. http://www.breastcancerindia.net/statistics/stat_globa l.html Comparison Globacon 2008 v/s Globacon 2012.

2. http://www.breastcancerindia.net/statistics/stat_globa l.html WHO prediction for breast cancer in India and http://globocan.iarc.fr.

3. Willer W. (1990), Nutritional epidemiology. New York NY: Oxford University Press.

4. Ursin G. Longnecker MP et al. (1995). A meta-analysis of body mass index and risk of premenopausal breast cancer. Epidemiology 1995;6:137-41.

5. Ballard-Barbash R. et al. (1990) Body fat distribution and breast cancer in Framingham study. J Natl Cancer Inst 1990;82(4):286-90.

6. Stoll B A. (1998 Nov.). Teenage obesity in relation to breast cancer risk. Journal of International Association for study of obesity. Nov. 1998;22(11):1035-40.

7. Dorgan J F et al. (1995). Relation of body size to plasma level of estrogen and androgen in premenopausal women (Maryland, United States). Cancer causes \& Control, January 1995;6:3-8.

8. Sonnenschein E, Toniolo P. (1999 Dec.). Body fat distribution and obesity in pre- and postmenopausal breast cancer. Int J Epidimol 1999 Dec;28(6):1026-31.

9. Franceschi S. et al. (1996). Body-size indices and breast cancer risk before and after menopause. Int J Cancer 1996;67:181-6.

10. Zhang S, Folsom AR (1995). Better breast cancer survival for postmenopausal women, who were less overweight and eat less fat. The Iowa Women's health study. Cancer, 1995 July15;76(2):275-83.

11. London SJ, Colditz GA et al. (1989 Nov. 24). Prospective Study of relative weight, height, and risk of breast cancer. JAMA 1989 Nov. 24;262(20):2853-8.

12. Burning PF et al. (1987). Endogenous estrogen and breast cancer: A possible relationship between body fat distribution and estrogen availability. J Steroid Biochem 1987;27:487-92.

13. Petrek JA, Peters M et al. (1993). Is body fat topography a risk factor for breast cancer? Ann Intern Med 1993;118:356-62.

14. Toniolo PG, Levitz M et al. (1995). A prospective study of endogenous oestrogen and breast cancer in postmenopausal women. J Natl Cancer Inst 1995;87:190-97.

15. Den Tonkelaar I, Seidell JC, Collette HJ (1995). Body fat distribution in relation to breast cancer in women participating in Dom-Project. Breast Cancer Res Treat 1995;34(1):55-61.

16. Schreier LE, Berg GA et al. (1999 Apr.). Lipoprotein alteration, abdominal fat distribution and breast cancer. Biochem Mol Biol Int 1999;47(4):681-90.

17. Folsom AR, Kaye SA et al. (1996). Increased incidence of carcinoma of breast associated with abdominal adiposity in post-menopausal women. Am J epidimiol 1996;131(5):794-803.

18. La Guardia M, Giammanco M et al. (2001). Breast Cancer and obesity. Panminerva Medica 2001;43(2):123-33.

19. Bernstein L, Ross RK (1993). Endogenous hormone and breast cancer risk. Epidemiol Rev 1993;15(1):48-65.

20. Daniell HW, Tam E, Filice A (1993). Large axillary metastases in obese women and smokers with breast cancer- an influence by host factors on early tumor behavior.

Breast Cancer Res Treat 1993;25(3):193-201.

21. Pekonen $\mathrm{F}, \mathrm{NyMan} \mathrm{T}$ et al. Insulin-like growth factor binding proteins in human breast cancer tissue. Cancer Research 1992;52(19):5204-5207.

22. Kohn EC and Liotta LA (1993). Invasion and metastasis: new approaches to an old problem. Onchology (Williston Park) 1993 Apr;7(4):47-52.

23. Maehle BO, Tretli S, Thorsen T (2004 Jun). The associations of obesity, Lymph node status and prognosis in breast cancer patients: dependence on estrogen and progesterone receptor status. APMIS 2004 Jun;112(6):349-57.

24. Banerjee D, Williams EV et al. (2001). Obesity predisposes to increased drainage following axillary node clearance: a prospective audit. Ann R Coll Surg Engl 2001;83(4):268-71.

25. Newmann LA, Kuerer HM et al. (2001). Reduction mammoplasty improves breast conservation therapy in patients with macromastia.

Am J Surg 2001;181(3):215-20.

26. Poikonen P, Biomqvist C, Joensuu H (2001). Effect of obesity on the leukocyte nadir in women treated with adjuvant cyclophosphamide, methotrexate and fluorouracil dosed according to body surface area. Acta Oncol 2001;40(1):67-71.

27. Van den Brandt PA, Spiegelman D et al. (2000 Sept 15). Pooled analysis of prospective cohort studies on height, weight, and breast cancer risk. Am J Epidemiol 2000 Sept;152(6):154-27.

28. Morimoto LM, White E et al. (2002 Oct.). Obesity, body size and risk of postmenopausal breast cancer: the Women's Health Initiative (United States). Cancer Causes Control 2002;13(8):741-51. 
29. Lahmann PH, Hoffmann K et al. (2004 Sep 20). Body size and breast cancer risk: findings from Europian Prospective Investigation In to Cancer and Nutrition (EPIC). Int J Cancer 2004;111(5):762-71.

30. Tehard B, Lehmann PH et al. (2004 Aug 20). Anthropometry, breast cancer and menopausal status: use of repeated measurements over 10 years of follow up- results of French E3N women's cohort study. Int J Cancer 2004 Aug;111(2):264-9.

31. Sonnenschein E, Toniolo P et al. (1999 Dec.), Body fat distribution and obesity in pre- and post-menopausal breast cancer. Int J Epidimol 1999 Dec;28(6):1026-31.

32. Kandish M, Tan PCJ (2004 Aug). Inverse relationship between body mass index and premenopausal breast cancer risk in Malaysian women. Asia Pac J Clin Nutr 2004;13 (Suppl.):5171.

\begin{tabular}{|c|c|c|c|c|}
\hline \multirow{2}{*}{$\begin{array}{c}\text { Menopausal } \\
\text { Status }\end{array}$} & \multicolumn{2}{|c|}{ Cases } & \multicolumn{2}{c|}{ Controls } \\
\cline { 2 - 5 } & $\mathbf{N}$ & $\mathbf{\%}$ & $\mathbf{N}$ & $\mathbf{\%}$ \\
\hline Pre-menopausal & 24 & 48.00 & 23 & 46.00 \\
\hline Post-menopausal & 26 & 52.00 & 27 & 54.00 \\
\hline Total & $\mathbf{5 0}$ & $\mathbf{1 0 0 . 0 0}$ & $\mathbf{5 0}$ & $\mathbf{1 0 0 . 0 0}$ \\
\hline Table 1: Menopausal Status of Breast \\
Cancer Patients and Controls \\
\hline
\end{tabular}

\begin{tabular}{|c|c|c|c|c|}
\hline \multirow{2}{*}{ Age } & \multicolumn{2}{|c|}{ Cases (n = 50) } & \multicolumn{2}{c|}{ Controls (n = 50) } \\
\cline { 2 - 5 } & $\mathbf{N}$ & $\mathbf{\%}$ & $\mathbf{N}$ & $\mathbf{\%}$ \\
\hline$<30$ & 3 & 6.00 & 0 & 0.00 \\
\hline $31-40$ & 12 & 24.00 & 11 & 22.00 \\
\hline $41-50$ & 18 & 36.00 & 21 & 42.00 \\
\hline $51-60$ & 11 & 22.00 & 11 & 22.00 \\
\hline$>60$ & 6 & 12.00 & 7 & 14.00 \\
\hline Total & $\mathbf{5 0}$ & $\mathbf{1 0 0 . 0 0}$ & $\mathbf{5 0}$ & $\mathbf{1 0 0 . 0 0}$ \\
\hline Table 2: Age of Breast Cancer Patients and Controls \\
\hline
\end{tabular}

\begin{tabular}{|c|c|c|c|c|c|c|}
\hline \multirow[t]{2}{*}{ Stage } & \multicolumn{2}{|c|}{$\begin{array}{c}\text { Pre- } \\
\text { menopausal } \\
(n=24)\end{array}$} & \multicolumn{2}{|c|}{$\begin{array}{c}\text { Post- } \\
\text { menopausal } \\
(n=26)\end{array}$} & \multicolumn{2}{|c|}{ Total } \\
\hline & $\mathbf{N}$ & $\%$ & $\mathbf{N}$ & $\%$ & $\mathbf{N}$ & $\%$ \\
\hline $\begin{array}{l}\text { Stage I } \\
(\mathrm{n}=0)\end{array}$ & 0 & 0 & 0 & 0 & 0 & 0 \\
\hline $\begin{array}{l}\text { Stage II } \\
(\mathrm{n}=22)\end{array}$ & 7 & 29.1 & 15 & 57.1 & 22 & 44.0 \\
\hline $\begin{array}{c}\text { Stage III } \\
(\mathrm{n}=16)\end{array}$ & 10 & 41.6 & 6 & 23.0 & 16 & 32.0 \\
\hline $\begin{array}{r}\text { Stage IV } \\
(\mathrm{n}=15)\end{array}$ & 7 & 29.1 & 5 & 19.8 & 12 & 24.0 \\
\hline Total & 24 & 100.0 & 26 & 100.0 & 50 & 100.00 \\
\hline
\end{tabular}

\begin{tabular}{|c|c|c|c|c|c|c|c|c|}
\hline \multirow{3}{*}{ Weight (Kg) } & \multicolumn{4}{|c|}{ Pre-menopausal } & \multicolumn{4}{|c|}{ Post-menopausal } \\
\hline & \multirow{2}{*}{ Early Stage } & \multirow{2}{*}{ Advanced Stage } & \multicolumn{2}{|c|}{ Total } & \multirow{2}{*}{ Early Stage } & \multirow{2}{*}{ Advanced Stage } & \multicolumn{2}{|c|}{ Total } \\
\hline & & & $\mathbf{N}$ & $\%$ & & & $\mathbf{N}$ & $\%$ \\
\hline$<=40$ & 1 & 4 & 5 & 20.83 & 3 & 2 & 5 & 19.23 \\
\hline $41-50$ & 3 & 8 & 11 & 45.83 & 3 & 3 & 6 & 23.08 \\
\hline $51-60$ & 3 & 3 & 6 & 25.00 & 4 & 4 & 8 & 30.77 \\
\hline $61-70$ & 0 & 1 & 1 & 4.17 & 3 & 1 & 4 & 15.38 \\
\hline$>70$ & 0 & 1 & 1 & 4.17 & 2 & 1 & 3 & 11.54 \\
\hline Total & 7 & 17 & 24 & 100.00 & 15 & 11 & 26 & 100.00 \\
\hline & Table & Weight $\mathrm{V} / \mathrm{s}$ Sta & ng ir & Pre-and & ost-menopc & sal Women & & \\
\hline
\end{tabular}

\begin{tabular}{|c|c|c|c|c|c|c|}
\hline \multirow{2}{*}{$\begin{array}{c}\text { Weight } \\
\text { (Kg) }\end{array}$} & \multicolumn{2}{|c|}{ Pre-menopausal } & \multicolumn{2}{|c|}{ Post-menopausal } & \multicolumn{2}{|c|}{ Total } \\
\hline & $\mathbf{N}$ & $\%$ & $\mathbf{N}$ & $\%$ & $\mathbf{N}$ & $\%$ \\
\hline$<=40$ & 5 & 21.74 & 3 & 11.11 & 8 & 16.00 \\
\hline $41-50$ & 9 & 39.13 & 6 & 22.22 & 15 & 30.00 \\
\hline $51-60$ & 6 & 26.09 & 8 & 29.63 & 14 & 28.00 \\
\hline $61-70$ & 3 & 13.04 & 5 & 18.52 & 8 & 16.00 \\
\hline$>70$ & 0 & 0.00 & 5 & 18.52 & 5 & 10.00 \\
\hline Total & 23 & 100 & 27 & 100 & 50 & 100.00 \\
\hline \multicolumn{7}{|c|}{ Table 5: Weight of Controls } \\
\hline
\end{tabular}

\begin{tabular}{|c|c|c|c|c|c|c|c|c|}
\hline \multirow{3}{*}{ Height (cm) } & \multicolumn{4}{|c|}{ Pre-menopausal } & \multicolumn{4}{|c|}{ Post-menopausal } \\
\hline & \multirow{2}{*}{ Early Stage } & \multirow{2}{*}{ Advanced Stage } & \multicolumn{2}{|c|}{ Total } & \multirow{2}{*}{ Early Stage } & \multirow{2}{*}{ Advanced Stage } & \multicolumn{2}{|c|}{ Total } \\
\hline & & & $\mathbf{N}$ & $\%$ & & & $\mathbf{N}$ & $\%$ \\
\hline$<=130$ & 0 & 0 & 0 & 0.00 & 2 & 0 & 2 & 7.69 \\
\hline $131-140$ & 0 & 0 & 0 & 0.00 & 0 & 2 & 2 & 7.69 \\
\hline $141-150$ & 3 & 6 & 9 & 37.5 & 5 & 3 & 8 & 30.77 \\
\hline $151-160$ & 3 & 10 & 13 & 54.17 & 7 & 5 & 12 & 46.15 \\
\hline$>160$ & 1 & 1 & 2 & 8.33 & 1 & 1 & 2 & 7.69 \\
\hline Total & 7 & 17 & 24 & 100.00 & 15 & 11 & 26 & 100.00 \\
\hline
\end{tabular}




\begin{tabular}{|c|c|c|c|c|c|c|}
\hline \multirow{2}{*}{ Height (cms) } & \multicolumn{2}{|c|}{ Pre-menopausal } & Post-menopausal & \multicolumn{2}{c|}{ Total } \\
\cline { 2 - 7 } & $\mathbf{N}$ & $\mathbf{0}$ & $\mathbf{N}$ & $\mathbf{\%}$ & $\mathbf{N}$ & $\mathbf{\%}$ \\
\hline$<=130$ & 0 & 0.00 & 1 & 3.70 & 1 & 2.00 \\
\hline $131-140$ & 0 & 0.00 & 0 & 0.00 & 0 & 0.00 \\
\hline $141-150$ & 9 & 39.13 & 6 & 22.22 & 15 & 30.00 \\
\hline $151-160$ & 13 & 56.52 & 19 & 70.37 & 32 & 64.00 \\
\hline$>160$ & 1 & 4.35 & 1 & 3.70 & 2 & 4.00 \\
\hline Total & $\mathbf{2 3}$ & $\mathbf{1 0 0}$ & $\mathbf{2 7}$ & $\mathbf{1 0 0}$ & $\mathbf{5 0}$ & $\mathbf{1 0 0 . 0 0}$ \\
\hline \multicolumn{7}{|c|}{ Table 7: Height of Controls } \\
\hline
\end{tabular}

\begin{tabular}{|c|c|c|c|c|c|c|c|c|}
\hline \multirow[b]{3}{*}{ WHR } & \multicolumn{4}{|c|}{ Pre-menopausal } & \multicolumn{4}{|c|}{ Post-menopausal } \\
\hline & \multirow{2}{*}{ 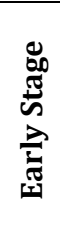 } & \multirow{2}{*}{ 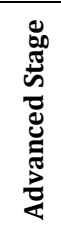 } & \multicolumn{2}{|c|}{ Total } & \multirow{2}{*}{ 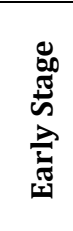 } & \multirow{2}{*}{ 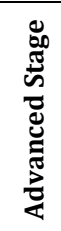 } & \multicolumn{2}{|c|}{ Total } \\
\hline & & & $\mathbf{N}$ & $\%$ & & & $\mathbf{N}$ & $\%$ \\
\hline$<=0.75$ & 0 & 4 & 4 & 16.67 & 1 & 0 & 1 & 3.85 \\
\hline $0.75-0.80$ & 2 & 4 & 6 & 25.00 & 8 & 2 & 10 & 38.48 \\
\hline $0.80-0.85$ & 3 & 5 & 8 & 33.3 & 3 & 6 & 9 & 54.46 \\
\hline $0.85-0.90$ & 1 & 3 & 4 & 16.67 & 1 & 2 & 3 & 11.54 \\
\hline$>0.90$ & 1 & 1 & 2 & 8.33 & 2 & 1 & 3 & 11.54 \\
\hline Total & 7 & 17 & 24 & 100.00 & 15 & 11 & 26 & 100.00 \\
\hline
\end{tabular}

\begin{tabular}{|c|c|c|c|c|c|c|}
\hline \multirow{2}{*}{ WHR } & \multicolumn{2}{|c|}{ Pre-menopausal } & \multicolumn{2}{c|}{ Post-menopausal } & \multicolumn{2}{c|}{ Total } \\
\cline { 2 - 7 } & $\mathbf{N}$ & $\mathbf{\%}$ & $\mathbf{N}$ & $\mathbf{\%}$ & $\mathbf{N}$ & $\mathbf{\%}$ \\
\hline$<=0.75$ & 2 & 8.70 & 0 & 0.00 & 2 & 4.00 \\
\hline $0.75-0.80$ & 3 & 13.04 & 4 & 14.81 & 7 & 14.00 \\
\hline $0.80-0.85$ & 6 & 26.09 & 12 & 44.44 & 18 & 36.00 \\
\hline $0.85-0.90$ & 9 & 39.13 & 10 & 37.04 & 19 & 38.00 \\
\hline$>0.90$ & 3 & 13.04 & 1 & 3.70 & 4 & 8.00 \\
\hline Total & $\mathbf{2 3}$ & $\mathbf{1 0 0}$ & $\mathbf{2 7}$ & $\mathbf{1 0 0}$ & $\mathbf{5 0}$ & $\mathbf{1 0 0 . 0 0}$ \\
\hline \multicolumn{7}{|c|}{ Table 9: WHR of Controls } \\
\hline
\end{tabular}

\begin{tabular}{|c|c|c|c|c|c|c|c|c|}
\hline \multirow[b]{3}{*}{ BMI } & \multicolumn{4}{|c|}{ Pre-menopausal } & \multicolumn{4}{|c|}{ Post-menopausal } \\
\hline & \multirow{2}{*}{ 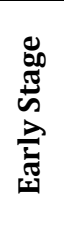 } & \multirow{2}{*}{ 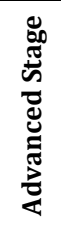 } & \multicolumn{2}{|c|}{ Total } & \multirow{2}{*}{ 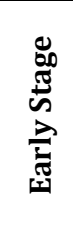 } & \multirow{2}{*}{ 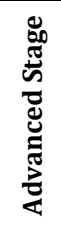 } & \multicolumn{2}{|c|}{ Total } \\
\hline & & & $\mathbf{N}$ & $\%$ & & & $\mathbf{N}$ & $\%$ \\
\hline$<=15$ (Underweight) & 0 & 0 & 0 & 0.00 & 2 & 0 & 2 & 7.69 \\
\hline 16-20 (Underweight) & 0 & 0 & 0 & 0.00 & 0 & 2 & 2 & 7.69 \\
\hline 21-25 (Desirable) & 3 & 6 & 9 & 37.5 & 5 & 3 & 8 & 30.77 \\
\hline 151-160 (Over weight) & 3 & 10 & 13 & 54.17 & 7 & 5 & 12 & 46.15 \\
\hline$>160$ (Obese) & 1 & 1 & 2 & 8.33 & 1 & 1 & 2 & 7.69 \\
\hline Total & 7 & 17 & 24 & 100.00 & 15 & 11 & 26 & 100.00 \\
\hline \multicolumn{9}{|c|}{ Table 10: BMI V/s Staging in Pre- and Post-menopausal Breast Cancer Patients } \\
\hline
\end{tabular}

\begin{tabular}{|c|c|c|c|c|c|c|}
\hline \multirow{2}{*}{ BMI } & \multicolumn{2}{|c|}{ Pre-menopausal } & \multicolumn{2}{c|}{ Post-menopausal } & \multicolumn{2}{c|}{ Total } \\
\cline { 2 - 7 } & $\mathbf{N}$ & $\mathbf{\%}$ & $\mathbf{N}$ & $\mathbf{\%}$ & $\mathbf{N}$ & $\mathbf{\%}$ \\
\hline$<=15$ & 1 & 4.35 & 0 & 0.00 & 1 & 2.00 \\
\hline $16-20$ & 10 & 43.48 & 4 & 14.81 & 14 & 28.00 \\
\hline $21-25$ & 8 & 34.78 & 8 & 29.63 & 16 & 32.00 \\
\hline $26-30$ & 4 & 17.39 & 9 & 33.33 & 13 & 26.00 \\
\hline$>30$ & 0 & 0.00 & 6 & 22.22 & 6 & 12.00 \\
\hline Total & $\mathbf{2 3}$ & $\mathbf{1 0 0}$ & $\mathbf{2 7}$ & $\mathbf{1 0 0}$ & $\mathbf{5 0}$ & $\mathbf{1 0 0 . 0 0}$ \\
\hline \multicolumn{7}{|c|}{ Table 11: BMI of Controls } \\
\hline
\end{tabular}

